\title{
Ageing International \\ Social Participation of the Elders in Europe: The Influence of Individual and Contextual Variables \\ --Manuscript Draft--
}

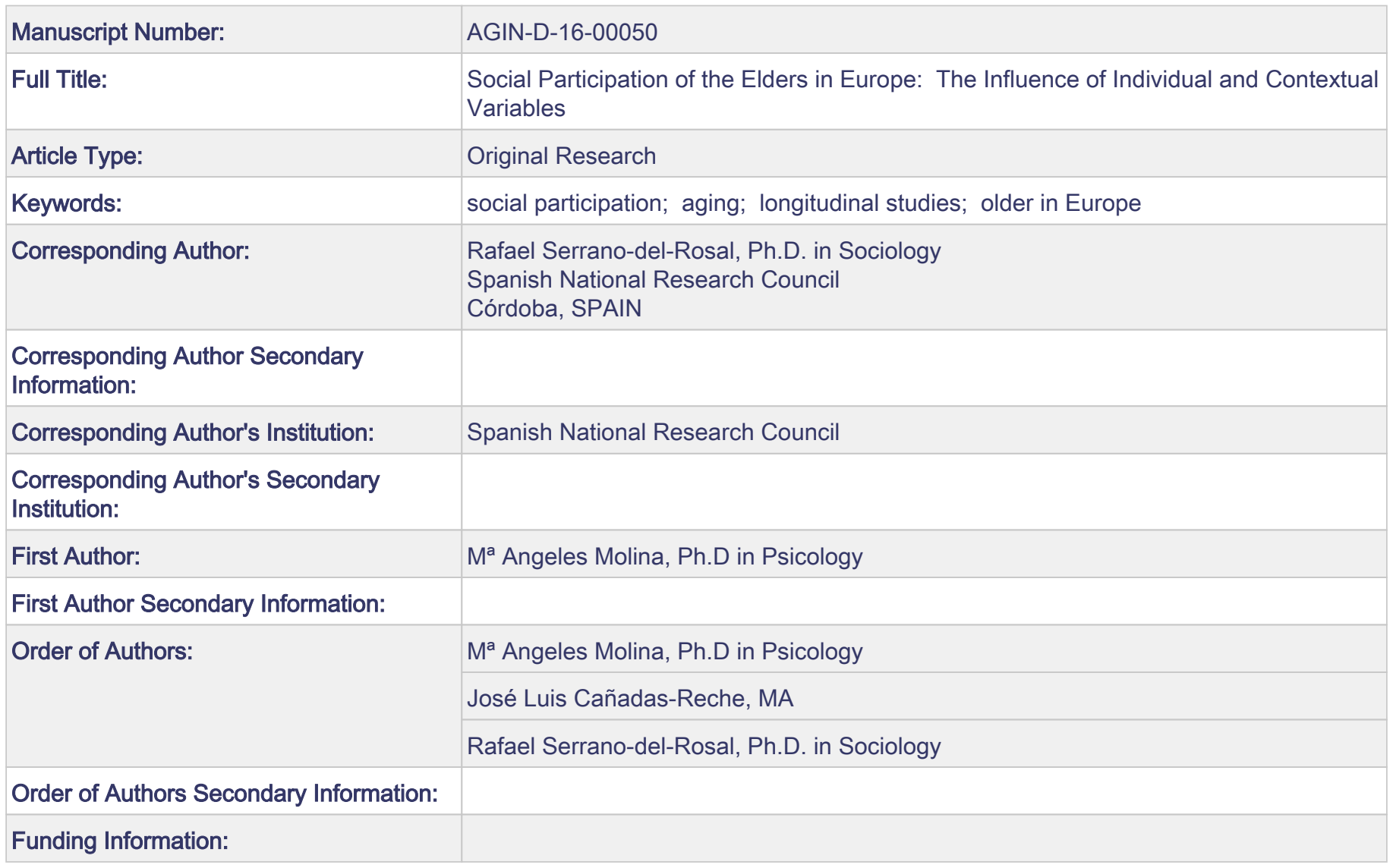




\section{Social Participation of the Elders in Europe:}

\section{The Influence of Individual and Contextual Variables}

$\mathrm{M}^{\mathrm{a}}$ Ángeles Molina, PhD. Assistant Professor at Francisco de Vitoria University and research at Institute for Advanced Social Studies and Institute of Economics, Geography and Demography. Spanish National Research Council.

Universidad Francisco de Vitoria

Ctra. Pozuelo-Majadahonda Km. 1.800

28223 Pozuelo de Alarcón (Madrid, España)

$\underline{\text { mangeles.molina@cchs.csic.es; } \text { mangeles2601@yahoo.es }}$

José L. Cañadas-Reche, MA. Senior Data Scientist at Synergic Partners.

C/ Gregorio Benítez $31^{\circ}$

28043 Madrid SPAIN

canadasreche@gmail.com $\square \square \square$ canadasreche@gmail.com

Rafael Serrano-del-Rosal, PhD. Institute for Advanced Social Studies. Spanish National Research

Council

(Corresponding author)

C/ Campo Santo de los Mártires, 7

14004-Córdoba, SPAIN

$\underline{\text { rserrano@iesa.csic.es }}$ 


\section{Acknowledgements}

This paper uses data from SHARE wave 4 release 1.1.1, as of March 28th 2013(DOI:

10.6103/SHARE.w4.111) and SHARE wave 1 and 2 release 2.6.0, as of November 292013 (DOI:

10.6103/SHARE.w1.260 and 10.6103/SHARE.w2.260). The SHARE data collection has been primarily funded by the European Commission through the 5th Framework Programme (project QLK6-CT-200100360 in the thematic programme Quality of Life), through the 6th Framework Programme (projects SHARE-I3, RII-CT-2006-062193, COMPARE, CIT5- CT-2005-028857, and SHARELIFE, CIT4-CT2006-028812) and through the 7th Framework Programme (SHARE-PREP, N ${ }^{\circ} 211909$, SHARE-LEAP, $\mathrm{N}^{\circ} 227822$ and SHARE M4, $\mathrm{N}^{\circ}$ 261982). Additional funding from the U.S. National Institute on Aging (U01 AG09740-13S2, P01 AG005842, P01 AG08291, P30 AG12815, R21 AG025169, Y1-AG-4553-01, IAG BSR06-11 and OGHA 04-064) and the German Ministry of Education and Research as well as from various national sources is gratefully acknowledged (see www.share-project.org for a full list of funding institutions).

\section{Conflct of interest}

$\mathrm{M}^{\mathrm{a}}$ Angeles Molina (author A) declares that she has no conflict of interest; Jose Luis Cañadas-Reche (author B) declares that he has no conflict of interest, and Rafael Serrano-del-Rosal (author C) declares that he has no conflict of interest 



\section{Social Participation of the Elders in Europe: The Influence of}

\section{Individual and Contextual Variables}

\section{Introduction}

A common stereotype about the group of older adults is that they are a "passive class" and that they are a burden on society (e.g., Becker and Schroots 2008; Butrica and Schaner 2005). In contrast to this stereotyped image, there is a more positive approach to understand and tackle old age as a state and as a process: active aging. The World Health Organization defines it as "the process of optimizing opportunities for health, participation and security in order to enhance quality of life as people age" (WHO 2002).

Active aging is a process that covers the whole life cycle, with the individual achieving high physical and cognitive functioning, a low probability of disease or disease-related disability and a high engagement to life (Rowe and Khan 1997).

The "engagement to life" factor in the field of social research has been studied and measured through social participation; as far as the group of older adults is concerned, this is specially valid, as it involves being present and active in social life, acknowledging the collective value of the elders in society (Fernández-Ballesteros et al. 2011; Mendes de León 2005).

Most definitions of social participation and other related concepts (social engagement, social capital, social support, social integration...) share the general idea that the interaction with others through the involvement in activities is essential (Levasseur et al. 2010). As regards the activities that are usually considered in the operationalization of social participation, a wide range is included: associationism, voluntary work, political activity, lifelong learning, leisure and free time, among others.

Many studies have revealed the relation between social participation and other functioning measures; thus, it has been related to preserving the cognitive function in old age (Lövdén, Ghisletta, and Lindenberg 2005; Crowe et al. 2003; Scarmeas et al. 2001), to maintaining good health (Sirven and Debrand, 2008), to longevity (Moen, Dempster-McClain and Williams 1989), and to high levels of psychological well-being (Beck Page 1988). 
The empirical research aimed to search for determining factors in social participation in old age has identified individual variables such as the level of education, occupation, age and health (Bukov, Maas and Lampert 2002). Although most of the times these variables have been studied from a strictly individual and transversal perspective empirically analyzing their interpersonal variability at a given moment in time, due to their characteristics it may certainly be interesting to analyze them from a cultural, social and longitudinal perspective, like the one cohorts may provide.

A cohort is defined as the aggregate of individuals who experience the same event within the same time interval; the defining event is commonly the year of birth (Ryder 1965). Each cohort has its peculiarities and is different from the rest. Therefore, the changes in the population pyramid that have been occurring entail changes in the successive generations that are aging. The characteristics and behaviors of the people who are approaching and will reach old age are different and will probably keep on changing as new generations reach this stage in life (Ramiro et al. 2012).

The individuals as socializing agents and agents of their own aging process, as well as the sociopolitical managers as those responsible for public policies, and the socio-cultural and economic context as the scene where all of them interact in a given moment and place, may intervene in the social participation of the elders. Thus, social participation may be influenced by individual characteristics, but also by contextual factors that go beyond them.

The aim of this work is to analyze social participation in old age on the basis of a model with the capacity to integrate individual variables (age, level of education, cognitive functioning) and contextual variables (cohort, country) at the same time. The analysis of the relative weight of these factors will allow us to discover where the changes taking place in social participation are leading to, making it possible to consider explanations both at the individual level (e.g., age) and the aggregate level (period and cohorts), which have as much to do with the life cycle as with socialization and the socio-political context.

\section{Design and methods}

The data used have been obtained from the Survey of Health, Ageing and Retirement in Europe (SHARE). SHARE is a longitudinal and multidisciplinary database of micro data of people over 50 in European countries (see www.share-project.org). Data from the baseline (W1) has been used in this 
study, as well as from waves two (W2) and four (W4). The first data collection took place in 2004-2005, the second wave was collected in 2006-2007, and the fourth one in 2010. Wave three is a retrospective survey focusing on respondents' life stories; the questions in this survey are not comparable with the other waves, that is why it was not included in this study. Details about the research and methodology of the analyzed waves may be found in Börsch-Supan and Jürges, 2005; Borsch-Supan et al, 2013, and Malter, Börsch-Supan, 2013.

The information about social participation was obtained from the questions: "Please look at card 35. Have you done any of these activities in the last month?" in waves W1 and W2, and "Please look at card 34: which of the activities listed on this card - if any - have you done in the past twelve months?" in wave W4. The following response categories where included: voluntary or charity work, attended an educational or training course, gone to a sport or social club, taken part in religious or political organizations. With the aim of being able to compare the questions from waves W1 and W2 with those of W4, the response frequency was taken into account. The participation variable was defined as a dichotomous variable ("has participated / has not participated"), coding answers as "has participated" whenever the respondents said that they had done at least one of the included activities. In W4, when respondents said that they had done at least one of the activities every day, week or month or most of the months of the year, their answer was coded as "has participated". In this last wave, if the respondent said that during the year he or she had done one of these activities but less frequently, it was coded as "has not participated", so that the variable classifies participation situations with a similar minimum frequency. The original name of the variables may be found in Table 2.

The other variables considered were: birth cohort, country, age, wave of the study, level of education, cognitive functioning and self-perceived health.

As regards the age variable, it should be noted that two variables have been derived from it: age and squared age through transformation with orthogonal polynomials. With a change of base, the latter makes it possible to consider the linear and quadratic effects of age with no collinearity between both variables (see Kleinbaum 2013; Shacham and Brauner 1997).

As regards the cognitive functioning variable, a cognitive score index was calculated. This index involves the following items (Dewey and Prince 2005): naming correctly the day of the week, day of the month, month and year (one point for each correct answer, maximum: four); an immediate and a delayed 10-word recall test (one point for each correct answer, maximum: 20); a mathematical performance test 
(one point for each correct answer, maximum: five). For missing cognitive indexes we computed scores of zero. The range of cognitive functioning is 0-29.

In order to explain the relation between participation (dichotomous variable) and the rest of variables of interest, a logistic regression model has been considered. As SHARE is a longitudinal survey, the respondents' answers in the different waves are not independent (the same person may answer in more than one wave and it is clear that their answer to the same question in one wave is somehow related to their answer in the other wave(s)). Considering a classic model where this correlation structure was not included might lead to spurious relations. Therefore, a multilevel logistic regression must be considered, where at least one of the levels is the variable identifying the respondent.

In order to reach the objective of this research, apart from modeling the variation among the respondents, it has been deemed appropriate to also model the variation among cohorts and countries. Including the cohort variable in a level higher than the individual level enables to separate its effect from the effect of age, as well as solving the problem of high collinearity among age, cohort and year of survey.

The reason why the country level is considered is the data's structure, as the surveys were conducted in different countries and not at the same time.

Thus, the variation structure used in the model has four levels. The first level corresponds to the answers given in each wave, the second level corresponds to the individuals themselves, the third level would be the country of origin, and the fourth level would be the birth cohort. Note that the first three levels are hierarchized (answers, subjects, country of origin of the subject), while the fourth level is crossed with the country level (within each cohort there are individuals from different countries).

There are two clearly different parts in the formulation of the model: on the one hand, the part of the so-called fixed effects, which would be equivalent to a classic logistic regression model; on the other hand, the part of the random effects, which takes into account other sources of variability.

In the final adjusted model, the fixed effects part may be expressed as

$$
\begin{aligned}
& \mathrm{P}\left[\text { Participation }_{i}\right]=\operatorname{logit}^{-1}\left(\alpha_{0}+\alpha_{j[i]}^{\text {subject }}+\alpha_{k[i]}^{\text {cohort }}+\alpha_{l[i]}^{\text {country }}+\beta_{1} \cdot \text { age }+\beta_{2} \cdot \text { age }^{2}\right. \\
& +\beta_{3} \cdot \text { Wave }_{2}+\beta_{4} \cdot \text { Wave }_{4}+\beta_{5} \cdot \text { eduyears }+\beta_{6} \cdot \text { cognitive } \\
& +\quad \beta_{7} \cdot \operatorname{sphus}(\text { verygood })+\beta_{8} \cdot \operatorname{sphus}(\operatorname{good}) \\
& \left.+\quad \beta_{9} \cdot \operatorname{sphus}(\text { fair })+\beta_{10} \cdot \operatorname{sphus}(\text { poor })\right)
\end{aligned}
$$

where $\operatorname{logit}^{-1}(x)=\frac{1}{1+\exp (-x)}$ 
In the part of random effects, the intercepts associated to subject, cohort and country are modeled, so

that

$$
\begin{array}{llll}
\alpha_{j}^{\text {subject }} & \sim & \mathcal{N}\left(0, \sigma_{\text {subject }}^{2}\right) \text { for } \mathrm{j}=1, \ldots, 40193 \\
\alpha_{k}^{\text {cohort }} & \sim & \mathcal{N}\left(0, \sigma_{\text {cohort }}^{2}\right) \text { for } \mathrm{k}=1, \ldots, 9 \\
\alpha_{l}^{\text {country }} & \sim & \mathcal{N}\left(0, \sigma_{\text {country }}^{2}\right) \text { for } \mathrm{l}=1, \ldots, 10
\end{array}
$$

The main difference if compared with classic logistic regression models is the inclusion of certain categorical variables as random effects. For the variables considered in the part of random effects, instead of estimating the coefficients associated to codification through dummy variables, the variance of the probability distribution is estimated, thereby the model is more parsimonious. In our case, using a classic analysis would have made it impossible to include the subject variable in the model, as it would entail more than 40,000 parameters, and that is computationally unfeasible.

The process to adjust and select variables has been carried out using the lme4 package (Bates et al. 2014) for language $\mathrm{R}$ (R CoreTeam 2014). As a first stage a multilevel logistic regression was adjusted, where the variables of respondent, cohort and country were included in the part of random effects. Later, other variables were added in the part of fixed effects and the obtained models were checked on the basis of the Akaike Information Criterion (AIC), until a model was reached in which the inclusion of other variables did not improve the previous model.

\section{Results}

In Table three, the column corresponding to the final model shows the estimated coefficients, their standard errors and the associated p-values. In that table it is not possible to appreciate the size of the effects of the fixed effects variables on participation. In order to visualize both the effect and the statistical signification, the charts of the mean effects have also been made (Figure 1), representing the estimated participation in relation to the different variables of the model, adding the confidence intervals at 95 per cent. A minor effect of the waves is observed, estimating a higher participation in the most recent waves. As regards age, there is more participation in the 60-70 age range, where participation is over 60 per cent. The cognitive functioning and years of education are strongly associated to the increase in participation, with a direct relation in both cases: the higher the cognitive functioning and the more years of education, the higher the participation. As expected, self-perceived health is also associated to 
the level of participation, with more participation from people who have a better perception of their own health.

The analysis of the variables introduced in the part of random effects is carried out from two approaches. In the first case, the percentage of variability explained by each variable (subject, country and cohort) is calculated. To that end, the intraclass correlation coefficient is obtained, which, for a factor $u$, is defined as:

$$
\rho_{u}=\frac{\sigma_{u}^{2}}{\sigma_{u}^{2}+\sigma_{\text {other random effects }}^{2}+\sigma_{e}^{2}}
$$

where $\sigma_{u}^{2}$ is the variance estimated by the model for the factor $u$ and $\sigma_{e}^{2}$ is the residual variance. In the case of the logistic regression $\sigma_{e}^{2}=\pi^{2} / 3$, the intraclass correlation coefficient ranges from zero if grouping conveys no information to 1 if all members of a group are identical (Gelman and Hill 2007). Thus, for the final model:

$$
\begin{gathered}
\rho_{\text {Subject }}=\frac{1.90}{1.90+0.27+0.01+\pi^{2} / 3}=0.35 \\
\rho_{\text {country }}=\frac{0.27}{1.90+0.27+0.01+\pi^{2} / 3}=0.05 \\
\rho_{\text {cohort }}=\frac{0.01}{1.90+0.27+0.01+\pi^{2} / 3}=0.02
\end{gathered}
$$

The variability explained by the variation among subjects is 35 per cent, five per cent by country, and two per cent by cohort. Table three shows how the estimated variance corresponding to cohorts and countries decreases as explanatory variables are introduced in the model, while the one corresponding to subjects remains stable. This performance seems to indicate that part of the variability explained by countries and cohorts in the models with fewer variables is in fact due to other variables. This is a very interesting result because, naturally, belonging to a certain country or cohort is not important per se but because there is a group of elements of the culture, the socioeconomic environment and other spheres which, altogether, may be collected even if aggregately only if we take into account this type of levels that go beyond the individuals but are necessarily influencing them somehow. 
Secondly, the model does not estimate the effect of each variable category on the participation (of Unbiased Prediction, BLUP (Robinson 1991). In fact, it has been proven that the estimates made through BLUP are usually more efficient than the traditional estimates using BLUE (Best Linear Unbiased Estimation) (Lax and Phillips 2009; Rao 2003).

As in the case of fixed effects, the charts representing the estimated participation have been made (Figure 2). As far as the cohorts are concerned, there are big differences between the "older" ones (people born before 1930), with a participation of less than 30 per cent, and the subsequent cohorts, where the estimated participation is around 45-50 per cent (Figure 2). The higher confidence interval for the 19601965 cohort reflects a greater instability in their participative behavior; this is the cohort with the smallest number of respondents. Figure 3 shows the participation pattern by cohort and wave of the study; those belonging to the cohorts of people born after 1935 have experienced an increase in their average participation, showing an increase of ten points from the first wave. As stated above, the variability explained by grouping respondents in the different cohorts is very low, although there are significant differences among cohorts, as shown by the confidence intervals (Figure 2).

The low intraclass correlation coefficient for the cohort shows that, in principle, it would not be necessary to include this variable in the part of random effects but in the part of fixed effects. However, it has been left in the part of random effects to separate its effect from that of age, as there is a high correlation between both variables.

The estimated effects for country (Figure 4) also show an important result: a clear North-South pattern. More precisely, in the most northern countries (Denmark, Sweden), together with the Netherlands and Switzerland, the participation is 50 per cent or higher. This is in clear contrast to participation in countries such as Spain and Italy, both because of a lower participation of older adults in all age ranges in the latter and because of the stage of life when participation begins to drop sharply.

Indeed, analyzing how the participation pattern shifts according to age and wave within each country (Figure 5), the differences among the different countries may be more clearly observed. While in most of the countries in each wave the age range where there is a greater participation is between 50 and 70, with a marked decrease from 70 on, in Spain and Italy there is a completely different pattern, not only because there is less participation in all age ranges, but also because participation begins to drop from 60 years of age on. 


\section{Discussion}

The methodologically constructed measurement of social participation includes, as stated above, different activities considered in aggregate, which would call for a more detailed analysis of the phenomenon if the objective is to learn about the type or form of social participation. However, that was not the objective of this work, as the involvement of anyone in the activities considered accounts for the social participation of the group of the elders and acknowledges it, empirically supporting the theoretical perspectives that do not consider it as a social group exclusively consuming resources, but rather a source of social resources which is undervalued today. This is why rather than analyzing each type of activity, the focus has been on participation, which made an aggregate measure more interesting, making it possible to approach the contribution of this group to the community. The activities considered under the concept of social participation have been conceptualized by other authors as "formal social participation" (Ferraro 1984; Utz et al. 2002).

In contrast to the widespread stereotype of older adults being a "passive class" and a burden on society (e.g., Becker et al. 2008; Butrica et al. 2005), the analysis of the empirical reality made in this work reveals a different image, as the participation rate is over 60 per cent between 60 and 70 years of age, and more than half of the respondents is still engaged in activities in society, even at advanced ages. It is no coincidence that the transit to retirement and the first years of retirement coincide temporally with the highest rates of social participation. Different studies have pointed to the involvement in activities after retirement as one of the factors with a positive effect on the process of adaptation to retirement (Wang, Henkens and van Solinge 2011; Dorfman and Douglas 2005; Kim and Feldman 2000). However, it is important to point out that the analyzed data empirically support two opposing theories; in the case of the younger elders, certain activities (labor) are replaced with others (activities in and for society), in accordance with the activity theory (Havinghurst 1961), while in the case of the older elders, the individual gradually disengages from community life, as proposed by the disengagement theory (Cumming and Henry 1961). Hence, rather than opposing theories, the obtained data point to a greater applicability of either one depending on the moment of old age considered. Nevertheless, at this point the huge heterogeneity of older adults must be noted, and while a generalist statement has been made, this does not reject the recognition of an interindividual variability (Neugarten 1975). 
As regards the results obtained from the model, the following conclusions may be drawn:

First of all, after controlling the contextual variables, the effects of the individual variables maintain their level of significance. This points to the validity of generating models explaining social participation on the basis of individual characteristics. In the obtained model, self-perceived health, cognitive functioning and level of education are explicative factors. These variables are interrelated in many studies: social participation and cognitive functioning (e.g.: Bassuk, Glass and Berkman 1999; Zunzunegui et al. 2003; Lóvden et al. 2005), social participation and health (e.g.: Young 1998; Fried 2004), social participation and level of education (Wu, Tang and Yan 2005; Kim et al. 2007), level of education and health (e.g.: Eikemo 2008; Laaksonen 2008), or level of education and cognitive functioning (e.g.: Bennett 2003; Evans 1993).

Secondly, although the effect of the contextual variables seems to share much of its variance with the individual variables (which is obvious and also supports the idea of the influence of the environment and the social context on individuals), it is still significant. This elaborates on the idea of a greater completeness of a model like the one we propose. This type of variables transcending individual factors provides information on questions that have not been collected in the individual field. For instance, the level of education is considered as a personal variable but, at the same time, it is a fact that there are generational gains regarding educational attainment and differences among countries in this variable (Barro and Lee 1993; Barro and Lee 2001). This illustrates how individual differences are at the same time the ones marking the differences among cohorts and countries, but also, aggregately, turn into elements transcending them somehow. In this regard, it is very important to take into account the brief period of time covered by SHARE, which makes it difficult for the comparison among cohorts to have had a greater influence in the model. However, even with this limitation in the data, there is a significant effect that may be confirmed in the model and could be greater if the time range were longer.

We consider that the different rate of social participation found among the different countries analyzed is also an interesting result, and the more so when it occurs beyond individual differences, as proven by the proposed model. This result encourages a line of research inquiring into the causes of this inequalities taking into account sociocultural longitudinal factors which are reflected in individual behaviors. In this regard, together with comparisons based on macro data, the search for explanations should tend toward a compared analysis of policies promoting social participation and in favor of older 
adults. Thus it is striking to have observed a restrictive change regarding participation on the basis of age in all countries, but at an especially early age in the case of Spain and Italy.

Inquiring into the patterns of the variation rate of social participation in different environments and stages in old age and their causes must be one of the focuses of future research. If this is not done, it is easy to end up making unfounded generalizations about a group of citizens with an ever-increasing presence in European societies. What is more, social policy managers should take into account this type of findings when planning their policies. New generations of older adults, more educated and in better health conditions, will reach old age; this must be taken into account in order to promote the social participation of the elders and to provide contexts facilitating and giving visibility to the contribution of this group to society.

\section{Compliance whith Ethical Standards}

All procedures performed in studies involving human participants were in accordance with the ethical standards of the institutional and/or national research committee and with the 1964 Helsinki declaration and its later amendments or comparable ethical standards.

\section{Conflict of Interest}

The authors declare that they have no conflict of interest.

\section{Informed Consent}

Informed consent was obtained from all individual participants included in the study.

\section{Ethical Treatment of Experimental Subjects (Animal and Human)}

This article does not contain any experimental studies with human or animal subjects performed by any of the authors. 


\section{References}

Barro, R. J., and Lee, J. W. 1993. International comparisons of educational attainment. Journal of monetary economics, 32,3, 363-394.

Barro, R. J., and Lee, J. W. 2001. International data on educational attainment: updates and implications. Oxford Economic papers, 53,3, 541-563.

Bassuk, S. S., Glass, T. A., and Berkman, L. F. 1999. Social disengagement and incident cognitive decline in community-dwelling elderly persons. Annals of internal medicine, 131,3, 165-173.

Bates, Douglas, Martin Maechler, Benjamin M. Bolker, and Steven Walker. 2014. Ime4: Linear MixedEffects Models Using Eigen and S4. http://arxiv.org/abs/1406.5823

Beck, S. H., and Page, J. W. 1988. Involvement in activities and the psychological well-being of retired men. Activities, Adaptation and Aging, 11,1, 31-47.

Becker, H. A., and Schroots, J. J. F. (Eds.). 2008. Releasing the Potentials of Senior Scholars and Scientists: Emerging Productivity in a New ERA. ERGO.

Bennett, D. A., Wilson, R. S., Schneider, J. A., Evans, D. A., De Leon, C. M., Arnold, S. E., Barnes, L.L., and Bienias, J. L. 2003. Education modifies the relation of AD pathology to level of cognitive function in older persons. Neurology, 60,12, 1909-1915.

Börsch-Supan, A. and H. Jürges (Eds.). 2005. The Survey of Health, Ageing and Retirement in Europe - Methodology. Mannheim Research Institute for the Economics of Aging (MEA), Mannheim.

Börsch-Supan, A., Brandt, M., Hunkler, C., Kneip, T., Korbmacher, J., Malter, F., Schaan, B., Stuck, S. and Zuber, S. 2013. Data Resource Profile: The Survey of Health, Ageing and Retirement in Europe (SHARE). International Journal of Epidemiology DOI: 10.1093/ije/dyt088.

Bukov, A., Maas, I., and Lampert, T. 2002. Social Participation in Very Old Age Cross-Sectional and Longitudinal Findings From BASE. The Journals of Gerontology Series B: Psychological Sciences and Social Sciences, 57,6, 510-517.

Butrica, B. A. and Schaner, S. G. 2005. Satisfaction and Engagement in Retirement. Perspective on Productive Ageing, 2. DC: Urban Institute, Washington,.

Crowe, M., Andel, R., Pedersen, N. L., Johansson, B., and Gatz, M. 2003. Does participation in leisure activities lead to reduced risk of Alzheimer's disease? A prospective study of Swedish twins. The Journals of Gerontology Series B: Psychological Sciences and Social Sciences, 58,5, 249-255. 
Cumming, E. y Henry, W. E. 1961. Growing Old: The process of Disengagement. Basic Books, New York.

de Leon, C. F. M. 2005. Social engagement and successful aging. European Journal of Ageing, 2,1, 6466.

Dewey, M. E., and Prince, M. J. 2005. Mental health. Health, ageing and retirement in Europe-First results from the Survey of Health, Ageing and Retirement in Europe. Mannheim Research Institute for the Economics of Aging, Mannheim, 108-117.

Dorfman, L. T., and Kolarik, D. C. 2005. Leisure and the retired professor: Occupation matters. Educational Gerontology, 31,5, 343-361.

Eikemo, T. A., Huisman, M., Bambra, C., and Kunst, A. E. 2008. Health inequalities according to educational level in different welfare regimes: a comparison of 23 European countries. Sociology of health and illness, 30,4, 565-582.

Evans, D. A., Beckett, L. A., Albert, M. S., Hebert, L. E., Scherr, P. A., Funkenstein, H. H., and Taylor, J. O. 1993. Level of education and change in cognitive function in a community population of older persons. Annals of epidemiology, 3,1, 71-77.

Fernández-Ballesteros, R., Zamarrón, M. D., Díez-Nicolás, J., López-Bravo, M. D., Molina, M. Á., and Schettini, R. 2011. Productivity in old age. Research on aging, 33,2, 205-226.

Ferraro, K. F. 1984. Widowhood and social participation in later life: Isolation or compensation? Research on Aging, 6,4, 451-468.

Fried, L. P., Carlson, M. C., Freedman, M., Frick, K. D., Glass, T. A., Hill, J., McGill, S., Rebok, G.w., Seeman, T., Tielsch, J., Wasik, B.A. and Zeger, S. 2004. A social model for health promotion for an aging population: initial evidence on the Experience Corps model. Journal of Urban Health, 81,1, 64-78.

Gelman, A., and Hill, J. 2007. Data Analysis Using Regression and Multilevel/Hierarchical Models.: Cambridge University Press, Cambridge, New York.

Havighurst, R. J. 1961. Successful aging. The Gerontologist. 1,1, 8-13.

Kim, J., Kang, J. H., Lee, M. A., and Lee, Y. 2007. Volunteering among older people in Korea. The Journals of Gerontology Series B: Psychological Sciences and Social Sciences, 62,1, S69-73.

Kim, S., and Feldman, D. C. 2000. Working in retirement: The antecedents of bridge employment and its consequences for quality of life in retirement. Academy of management Journal, 43,6, 1195-1210. 
Kleinbaum, David. 2013. Applied Regression Analysis and Other Multivariable Methods. Cengage Learning, Boston, MA.

Laaksonen, M., Talala, K., Martelin, T., Rahkonen, O., Roos, E., Helakorpi, S., Laatikainen, T., and Prättälä, R. 2008. Health behaviours as explanations for educational level differences in cardiovascular and all-cause mortality: a follow-up of 60000 men and women over 23 years. The European Journal of Public Health, 18,1, 38-43.

Lax, J.R, and Phillips, J.H. 2009. "How Should We Estimate Public Opinion in the States?” American Journal of Political Science, 53,1, 107-121.

Levasseur, M., Richard, L., Gauvin, L., and Raymond, É. 2010. Inventory and analysis of definitions of social participation found in the aging literature: Proposed taxonomy of social activities. Social Science and Medicine, 71,12, 2141-2149.

Lövdén, M., Ghisletta, P., and Lindenberger, U. 2005. Social participation attenuates decline in perceptual speed in old and very old age. Psychology and aging, 20,3, 423-434.

Malter, F., Börsch-Supan, A. (Eds.) 2013. SHARE Wave 4: Innovations and Methodology. MEA, Max Planck Institute for Social Law and Social Policy, Munich.

Moen, P., Dempster-McClain, D., and Williams Jr, R. M. 1989. Social integration and longevity: An event history analysis of women's roles and resilience. American Sociological Review, 635-647.

Neugarten, B. 1975. The future and the young old. The Gerontologist, 15, 4-9.

R Core Team. 2014. R: A Language and Environment for Statistical Computing. R Foundation for Statistical Computing, Vienna, Austria . http://www.R-project.org/.

Ramiro, D., Abellán, A., Durán, M.A., Fernández Mayoralas, G., Pérez-Díaz, J., Rodríguez, V. y Rojo, F. 2013. Una vejez Activa en España. EDIMSA, Madrid.

Rao, J. 2003. Small area estimation. John Wiley, Hoboken, N.J .

Robinson, G. K. 1991. That BLUP Is a Good Thing: The Estimation of Random Effects. Statistical Science. Institute of Mathematical Statistics 6,1.15-32. doi:10.1214/ss/1177011926. http://dx.doi.org/10.1214/ss/1177011926

Rowe, J. W., and Kahn, R. L. 1997. Successful aging. The Gerontologist, 37,4, 433-440.

Ryder, N. B. 1965. The cohort as a concept in the study of social change. American sociological review, 843861. 
Scarmeas, N., Levy, G., Tang, M., Manly, J. and Stern, Y. 2001. Influence of leisure activity on the incidence of Alzheimer's disease. Neurology, 57, 2236-2242.

Shacham, M., and Brauner, N. 1997.Minimizing the Effects of Collinearity in Polynomial Regression. Ind. Eng. Chem. Res American Chemical Society (ACS). 36,10. 4405-12. doi:10.1021/ie970236k. http://dx.doi.org/10.1021/ie970236k.

Sirven, N., and Debrand, T. 2008. Social participation and healthy ageing: An international comparison using SHARE data. Social Science and Medicine, 67,12, 2017-2026.

Utz, R. L., Carr, D., Nesse, R., and Wortman, C. B. 2002. The Effect of Widowhood on Older Adults' Social Participation An Evaluation of Activity, Disengagement, and Continuity Theories. The Gerontologist, 42,4, 522-533.

Wang, M., Henkens, K., and van Solinge, H. 2011. Retirement adjustment: A review of theoretical and empirical advancements. American Psychologist, 66,3, 204-213.

World Health Organization. 2002. Active Ageing. A Policy Framework. World Health Organization, Department of Health Promotion, Non-communicable Disease Prevention and Surveillance, Geneva, 1-60. http://whqlibdoc.who.int/hq/2002/who_nmh_nph_02.8.pdf

Wu, A. M., Tang, C. S., and Yan, E. C. 2005. Post-retirement voluntary work and psychological functioning among older Chinese in Hong Kong. Journal of Cross-Cultural Gerontology, 20,1, 2745.

Young, F. W., and Glasgow, N. 1998. Voluntary social participation and health. Research on Aging, 20,3, 339-362.

Zunzunegui, M. V., Alvarado, B. E., Del Ser, T., and Otero, A. 2003. Social networks, social integration, and social engagement determine cognitive decline in community-dwelling Spanish older adults. The Journals of Gerontology Series B: Psychological Sciences and Social Sciences, 58,2, S93-100. 
Figure 1. Estimated wave, age, cognitive functioning, years of education and self-perceived health effects. $95 \%$ confidence intervals have been added.
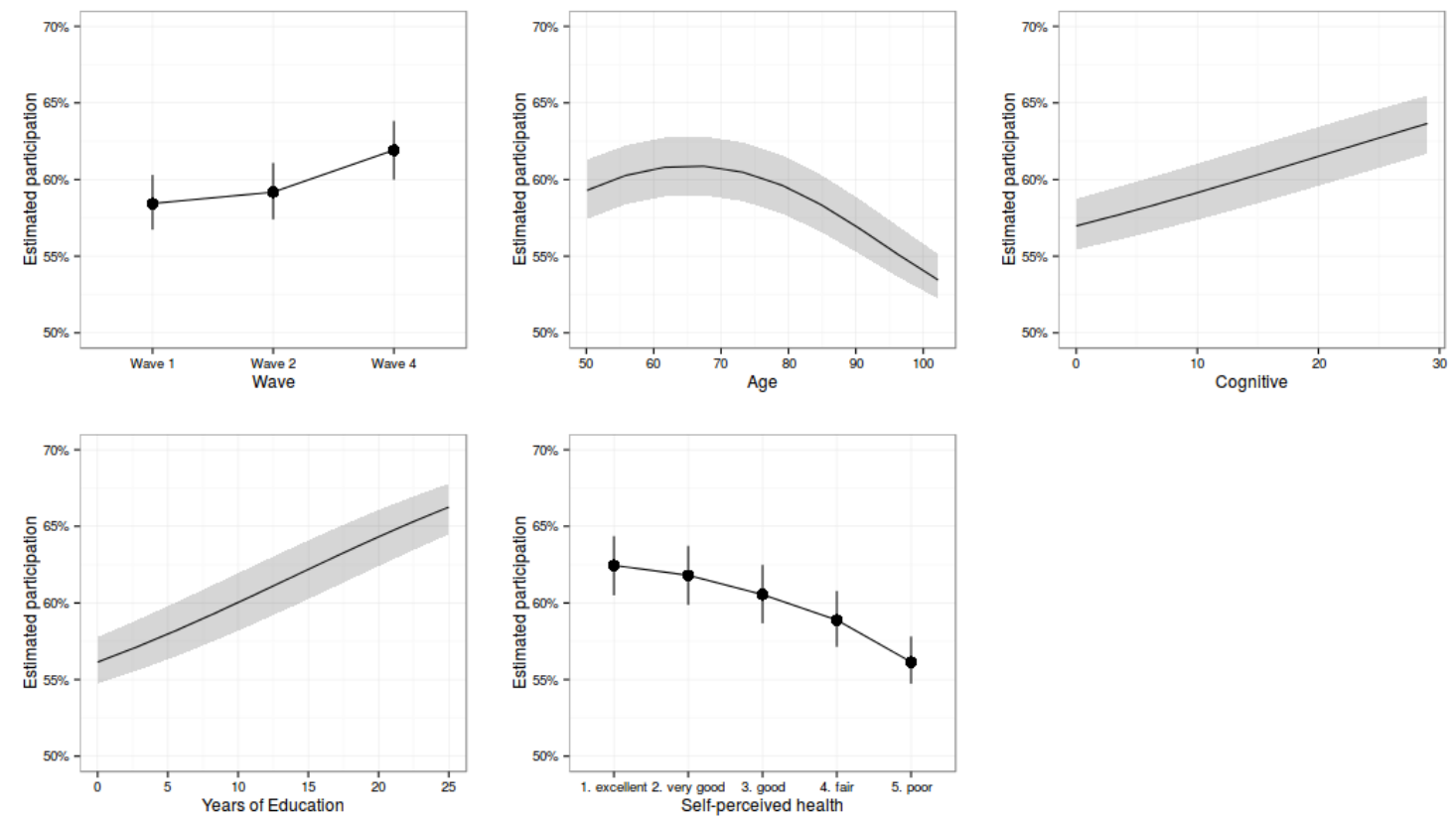
Figure 2. Estimated cohort effect. 95 per cent confidence intervals have been added.

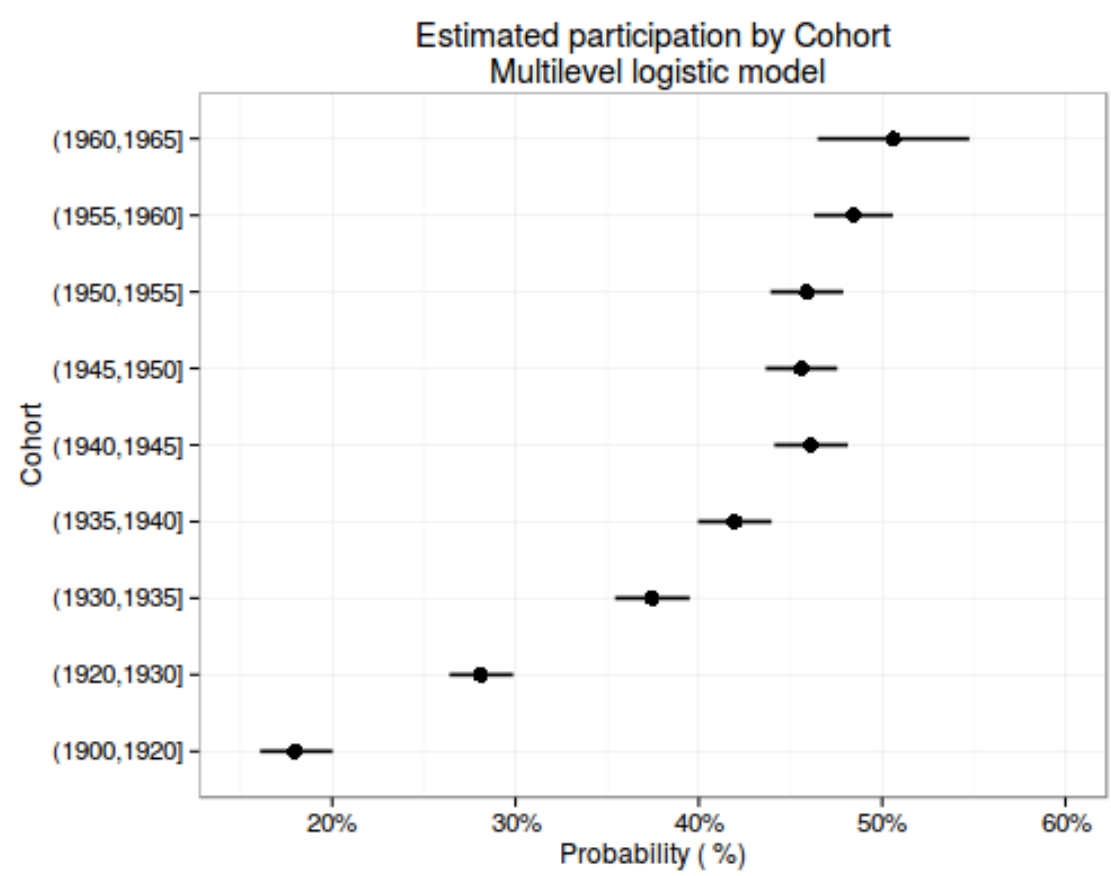


Figure 3. Estimated cohort means by wave.

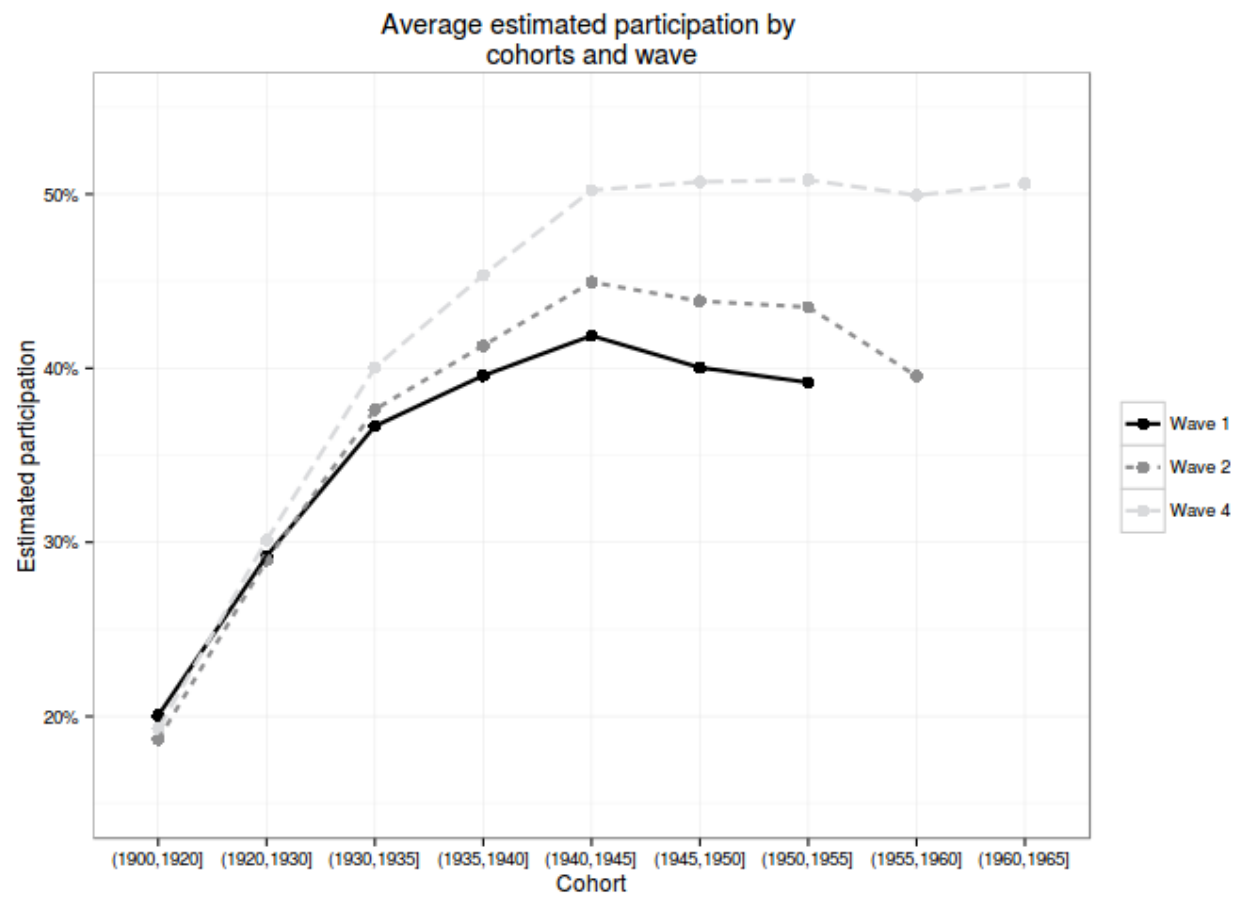


Figure 4. Estimated country effects. 95 per cent confidence intervals have been added.

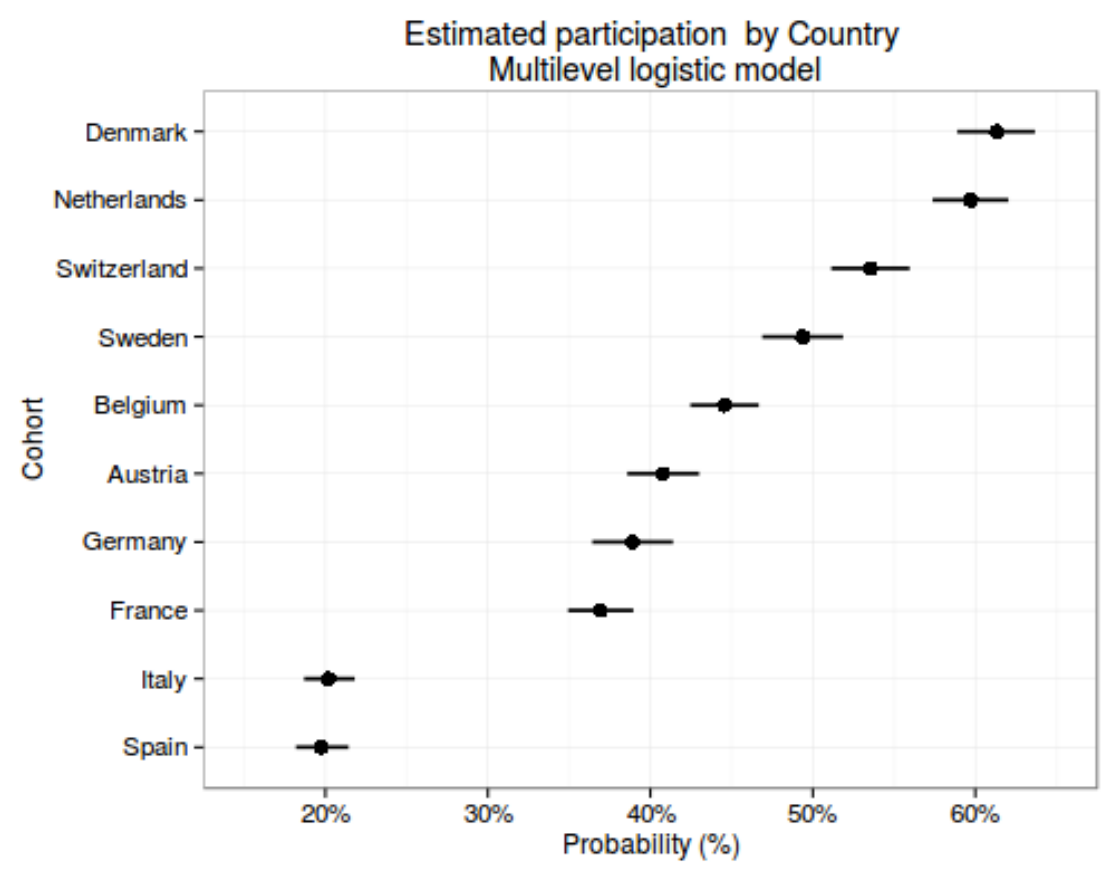


Figure 5. Change in the patterns of participation by age, country and wave. Each point represents the participation estimated by the model for each combination of age, country and wave. Smooth curves using local weighted regression have been adjusted to show trends.

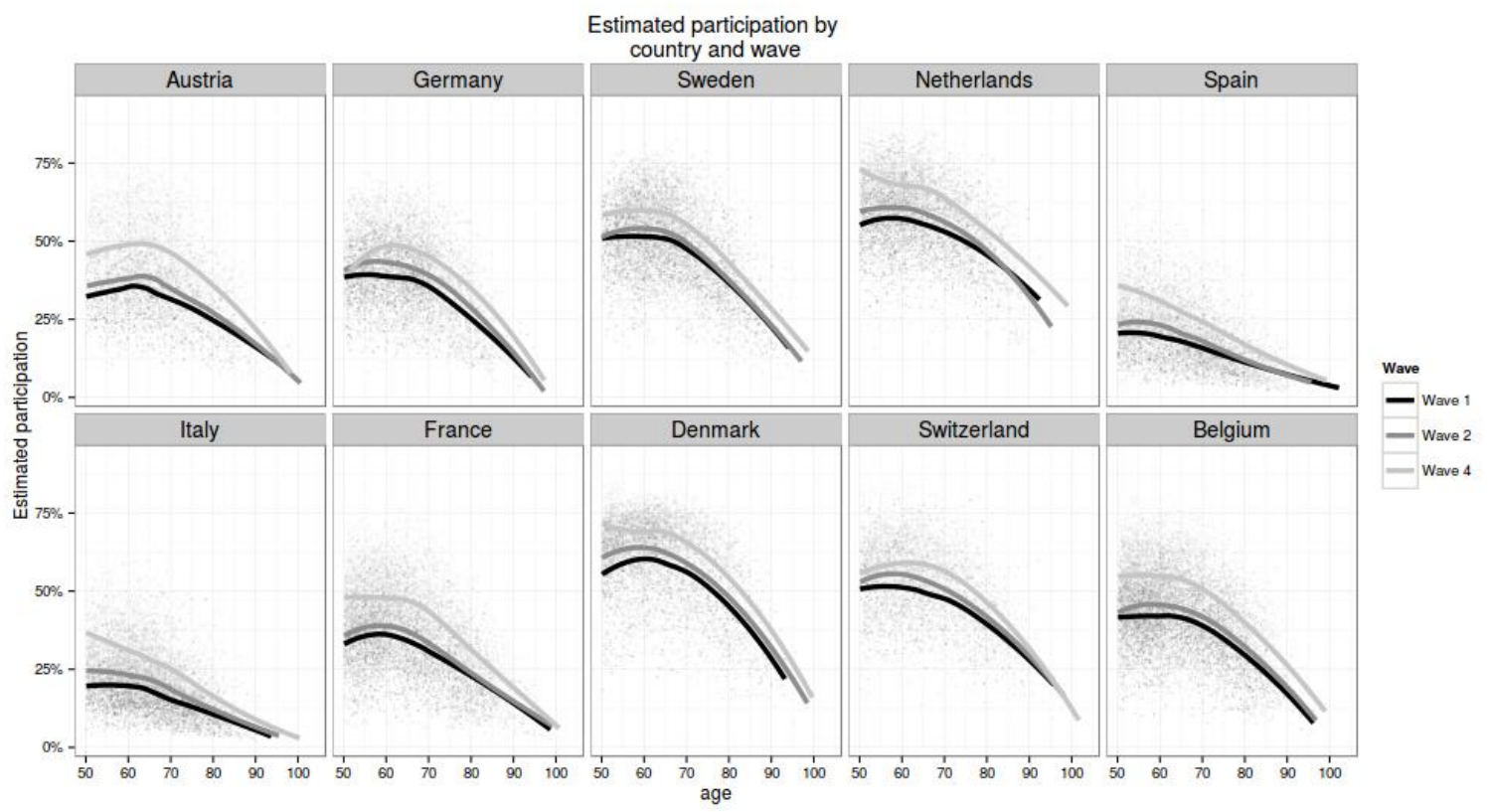


Table 1 . Sample by country and wave

\begin{tabular}{lrrrr}
\hline & Wave 1 & Wave 2 & Wave 4 & Total \\
\cline { 2 - 5 } Austria & 1526 & 1156 & 4907 & 7589 \\
Germany & 2870 & 2470 & 1526 & 6866 \\
Sweden & 2927 & 2651 & 1904 & 7482 \\
Netherlands & 2694 & 2553 & 2676 & 7923 \\
Spain & 2238 & 2036 & 3295 & 7569 \\
Italy & 2390 & 2800 & 3404 & 8594 \\
France & 2833 & 2703 & 5477 & 11013 \\
Denmark & 1562 & 2473 & 2184 & 6219 \\
Switzerland & 932 & 1401 & 3617 & 5950 \\
Belgium & 3576 & 2988 & 5051 & 11615 \\
Total (10 countries) & 23548 & 23231 & 34041 & 80820 \\
\hline
\end{tabular}


Table 2. Variables used to build participation indicator

\begin{tabular}{|c|c|c|}
\hline Description & Name in waves 1 and 2 & Names in wave 4 \\
\hline Done voluntary or charity work & $\operatorname{ac} 002 \mathrm{~d} 1$ & ac035d1 \\
\hline $\begin{array}{l}\text { Attended an educational or training } \\
\text { course }\end{array}$ & $\operatorname{ac002d4}$ & $\operatorname{ac} 035 d 4$ \\
\hline $\begin{array}{l}\text { Gone to a sport, social or other kind of } \\
\text { club }\end{array}$ & $\operatorname{ac} 002 \mathrm{~d} 5$ & $\operatorname{ac} 035 \mathrm{~d} 5$ \\
\hline $\begin{array}{l}\text { Taken part in activities of a religious } \\
\text { organization }\end{array}$ & ac002d6 & ac035d6 \\
\hline $\begin{array}{l}\text { Taken part in a political or community- } \\
\text { related organization }\end{array}$ & $\operatorname{ac} 002 \mathrm{~d} 7$ & $\operatorname{ac} 035 \mathrm{~d} 7$ \\
\hline
\end{tabular}


Table 3. Statistical models

\begin{tabular}{|c|c|c|c|c|c|c|c|}
\hline & Model 1 & Model 2 & Model 3 & Model 4 & Model 5 & Model 6 & Final \\
\hline \multirow[t]{2}{*}{$\overline{\text { (Intercept) }}$} & -0.44 & -0.46 & -0.38 & $-0.65^{* *}$ & $-1.50^{* * *}$ & $-2.22^{* * *}$ & $-1.66^{* * *}$ \\
\hline & $(0.30)$ & $(0.43)$ & $(0.40)$ & $(0.22)$ & $(0.20)$ & $(0.19)$ & $(0.18)$ \\
\hline \multirow[t]{2}{*}{ Age } & & $97.77^{* * *}$ & $89.78^{* * *}$ & $-73.85^{* * * *}$ & $-48.94^{* * * *}$ & $-25.33^{* * *}$ & $-17.28^{*}$ \\
\hline & & $(8.38)$ & $(8.44)$ & $(5.12)$ & $(5.37)$ & (7.49) & $(7.85)$ \\
\hline \multirow[t]{2}{*}{$\operatorname{Age}^{\wedge} 2$} & & & $-42.07^{* * *}$ & $-38.88^{* * * *}$ & $-45.53^{* * *}$ & $-38.72^{* * *}$ & $-36.68^{* * *}$ \\
\hline & & & $(4.87)$ & $(3.87)$ & $(4.22)$ & $(4.72)$ & $(4.78)$ \\
\hline \multirow[t]{2}{*}{ Wave 2} & & & & $0.20^{* * *}$ & $0.12^{* * *}$ & $0.09^{* * * *}$ & $0.13^{* * *}$ \\
\hline & & & & $(0.02)$ & $(0.03)$ & $(0.03)$ & $(0.03)$ \\
\hline \multirow[t]{2}{*}{ Wave 4} & & & & $0.51^{* * *}$ & $0.42^{* * *}$ & $0.59^{* * *}$ & $0.60^{* * *}$ \\
\hline & & & & $(0.02)$ & $(0.03)$ & $(0.03)$ & $(0.03)$ \\
\hline \multirow[t]{2}{*}{ Years of Education } & & & & & $0.09^{* * *}$ & $0.08^{* * *}$ & $0.07^{* * *}$ \\
\hline & & & & & $(0.00)$ & $(0.00)$ & $(0.00)$ \\
\hline \multirow[t]{2}{*}{ Cognitive } & & & & & & $0.05^{* * *}$ & $0.04^{* * *}$ \\
\hline & & & & & & $(0.00)$ & $(0.00)$ \\
\hline \multirow[t]{2}{*}{ Self-perceived } & & & & & & & $-0.11^{* *}$ \\
\hline & & & & & & & $(0.04)$ \\
\hline \multirow[t]{2}{*}{ Self-perceived } & & & & & & & $-0.32^{* * *}$ \\
\hline & & & & & & & $(0.04)$ \\
\hline \multirow[t]{2}{*}{ Self-perceived } & & & & & & & $-0.61^{* * *}$ \\
\hline & & & & & & & $(0.04)$ \\
\hline \multirow[t]{2}{*}{ Self-perceived } & & & & & & & $-1.15^{* * *}$ \\
\hline & & & & & & & $(0.06)$ \\
\hline AIC & 99816.05 & 99657.32 & 99562.06 & 99331.01 & 84494.10 & 83992.15 & 83144.78 \\
\hline BIC & 99853.20 & 99703.76 & 99617.79 & 99405.31 & 84576.37 & 84083.56 & 83272.75 \\
\hline Log Likelihood & - & - & - & - & - & - & - \\
\hline Deviance & 99808.05 & 99647.32 & 99550.06 & 99315.01 & 84476.10 & 83972.15 & 83116.78 \\
\hline Num. obs. & 79826 & 79826 & 79826 & 79826 & 68961 & 68961 & 68940 \\
\hline Num. groups: Subject & 49240 & 49240 & 49240 & 49240 & 40201 & 40201 & 40193 \\
\hline groups: & 10 & 10 & 10 & 10 & 10 & 10 & 10 \\
\hline Num. groups: Cohort & 9 & 9 & 9 & 9 & 9 & 9 & 9 \\
\hline Variance: & 1.93 & 1.96 & 1.96 & 1.94 & 2.05 & 1.99 & 1.90 \\
\hline Variance: & 0.49 & 0.51 & 0.51 & 0.48 & 0.36 & 0.32 & 0.27 \\
\hline Variance: & 0.36 & 1.19 & 0.99 & 0.00 & 0.00 & 0.01 & 0.01 \\
\hline
\end{tabular}

p** $<0.001,{ }^{* *} \mathrm{p}<0.01,{ }^{*} \mathrm{p}<0.05$

Statistical models 
Ma ÁNGELES MOLINA, PhD, is professor of Psychology at Francisco de Vitoria University and research at Spanish National Research Council. She researches on active aging, fourth age, cognitive plasticity in old age and stereotypes.

JOSE LUIS CAÑADAS-RECHE, Mastered in Statistics ,Graduated in Market Research Techniques and Senior Data Scientist at Synergic Partners.

His main working areas are: sampling techniques and estimation for social surveys, mixed and bayesian models techniques and using big data tools to estimate key performance indicators in telco sector

RAFAEL SERRANO-DEL-ROSAL has a PhD in Political Science and Sociology and he is Research Scientist at the Institute for Advanced Social Studies (Spanish National Research Council), where he currently directs the research line: Social Identity, Subjective Well-being and Human Behavior. His work and interests have focused on the confluence of three research areas: A) design, analysis and evaluation of public policies, B) subjective well-being and satisfaction and C) sociology of health. In all these fields he has directed numerous research projects and published their results in national and international journals as Medical Teacher, Applied Sociology, Social Indicators Research, Time and Society, Journal of Socio-economic and others. Currently he chairs the End of Life Research Network of which he is founder. 